\title{
High affinity iron acquisition in Rhizobium leguminosarum requires the CycHJKL operon and the feuPQ gene products, which belong to the family of two-component transcriptional regulators
}

\author{
Kay H. Yeoman, ${ }^{1} \dagger$ Maria-Jesus Delgado, ${ }^{2} \ddagger$ Margaret Wexler, ${ }^{1}$ \\ J. Allan Downie ${ }^{2}$ and Andrew W. B. Johnston ${ }^{1}$
}

Author for correspondence: Andrew W. B. Johnston. Tel: +44 1603 592264. Fax: +44 1603542250. e-mail: a.johnston@uea.ac.uk

1 School of Biological Sciences, University of East Anglia, Norwich NR4 7TJ, UK

2 John Innes Centre, Colney Lane, Norwich NR4 7UH, UK

\begin{abstract}
The cycHJKL operon of Rhizobium leguminosarum has previously been shown to be involved in the maturation of cytochrome $c$, possibly by its involvement in the covalent attachment of haem to the apoprotein. Mutations in the cycHJKL genes abolish symbiotic nitrogen fixation. Here, we show that cyc mutants are pleiotropically defective. They have lost a high affinity iron acquisition system due to their failure to make or to export siderophores. They also accumulate protoporphyrin IX, the immediate precursor of haem. A model to account for these phenotypes is presented. Immediately upstream of cycH is a gene, lipA, which is predicted to encode an outer-membrane lipoprotein. Further upstream of IipA, there are two other genes, whose products are similar in sequence to the widespread family of two-component transcriptional regulators. These two genes, feuP and feuQ, did not affect the transcription of lipA, or of the CyCHJKL operon. However, a mutation in feuQ also led to the loss of the high affinity iron uptake system, although siderophores were still produced.
\end{abstract}

Keywords: cytochrome $c$, iron acquisition, nitrogen fixation, Rhizobium, siderophore

\section{INTRODUCTION}

Iron is essential as a trace element for the growth of nearly all micro-organisms. Despite being the fourth most abundant element in the earth's crust, its extreme insolubility at normal biological $\mathrm{pH}$ severely decreases its bioavailability. To obtain sufficient iron for growth, most micro-organisms have developed high affinity iron acquisition systems. These usually involve the synthesis and export of siderophores, which are low-molecularmass ferric-ion-specific ligands. The iron-siderophore complex is recognized by an outer-membrane protein

†Present address: Institute of Food Research, Colney Lane, Norwich NR4 7UA, UK.

$\ddagger$ Present address: Estacion experimental del Zaidin, clo Professor Albareda, Granada, Spain.

Abbreviation: PPIX, protoporphyrin IX.

The EMBL accession number for the sequence reported in this paper is X89983. that is involved in the transport of the complex (Crosa, 1989; Guerinot, 1991; Reigh \& O'Connell, 1993). The majority of siderophores can be classified as either hydroxamates or catecholates, according to the main chelating group. One notable exception is rhizobactin produced by Sinorhizobium meliloti (formerly Rhizobium meliloti) DM4, which possesses ethylenediamine as a ligand (Smith et al., 1985).

Iron is of particular importance in the legume root nodules that are induced and occupied by species of the bacterial genera Rhizobium, Azorhizobium, Sinorhizobium and Bradyrbizobium. The iron-containing enzymes and proteins involved in nitrogen fixation include nitrogenase, ferredoxin, cytochromes and leghaemoglobin, the last being the single most abundant protein in the nodule. Iron also plays a regulatory role since it is involved in the oxygen-sensitive expression of the nitrogen fixation regulatory protein NifA (Fischer, 1994). The transcription of nif $A$ in $S$. meliloti is regulated by the genes $f x L$ and $f x J$ in response to a low-oxygen 
signal (Gilles-Gonzales et al., 1991) and FixL is known to be one of a group of haem-based sensors (Monson et al., 1995).

Nadler et al. (1990) isolated a mutant of Rhizobium leguminosarum biovar viciae (which nodulates peas and vetches) with a complex phenotype that included a defect in high affinity iron acquisition. This mutant, termed Pop116, was initially isolated because it fluoresced under UV light due to accumulated protoporphyrin IX (PPIX), the immediate precursor of haem that lacks iron. The mutant had at least two other defects; it had lower levels of $b$ and $c$-type cytochromes than the wild-type and it was completely unable to fix nitrogen in pea nodules although it formed bacteroids of essentially normal morphology. These pleiotropic effects were interpreted as being due to a defect in high affinity iron acquisition; thus, it was argued, cells that were irondeficient might be expected to accumulate PPIX, have low cytochrome content and be Fix ${ }^{-}$due to a lack of functional nitrogenase or other iron-containing proteins needed for nitrogen fixation.

In R. leguminosarum, S. meliloti and Bradyrbizobium japonicum, the cycHJKL genes are in a single operon (Delgado et al., 1995; Kereszt et al., 1995; Ritz et al., 1995). This operon is essential for the biogenesis of $c$ type haem proteins, and in rhizobia, mutations in cycHJKL completely abolish symbiotic nitrogen fixation. It has been speculated that the $c y c H J K L$ gene products are involved in the covalent attachment of haem to the apocytochrome $c$.

Homologues of $c y c H J K L$ have been found in a variety of other bacteria, including Escherichia coli (Thöny-Meyer et al., 1995) and Paracoccus denitrificans (Page \& Ferguson, 1995); two of them, $c y c K$ and $c y c L$, occur in Rhodobacter capsulatus, where they are referred to as ccl1 and ccl2, respectively (Beckman et al., 1992). Homologues have also been identified in chloroplasts (Ohyama et al., 1988) and in mitochondria (Pritchard et al., 1990). By a combination of functional and genetic comparisons, we show here that the pleiotropic phenotype found in the R. leguminosarum mutant Pop116 is, in fact, due to a mutation in the $c y c H J K L$ operon.

\section{METHODS}

Bacterial strains, plasmids and growth conditions. The strains used are shown in Table 1. General growth conditions for Rhizobium and E. coli were as described by Beringer (1974).

Growth in iron-deficient media. Iron was removed from $\mathrm{Y}$ minimal medium by adding $5 \mathrm{~g}$ Chelex resin $\mathrm{l}^{-1}$ (Bio-Rad) to $\mathrm{Y}$ medium lacking salts, and stirred at room temperature for $4 \mathrm{~h}$. The resin was removed by filtration, and the minimal medium salts added. Where necessary, uracil and tryptophan were added to final concentrations of $30 \mu \mathrm{g} \mathrm{ml}^{-1}$. Aliquots of medium $(100 \mathrm{ml})$ were dispensed into $250 \mathrm{ml}$ polypropylene Erlenmeyer flasks and autoclaved. Starter cultures were grown for $48 \mathrm{~h}$ in $\mathrm{Y}$ medium with no added iron, then $5 \mathrm{ml}$ volumes were inoculated into the Chelex-treated medium. Cultures were grown at $28^{\circ} \mathrm{C}$ on a rotary shaker until lateexponential phase. Cells were harvested by centrifugation, washed in iron-depleted medium, and subsequently used for siderophore production analysis and ${ }^{55} \mathrm{Fe}$-uptake studies.

Analysis of ${ }^{55} \mathrm{Fe}$ uptake. This was performed according to Nadler et al. (1990), with the following changes. Iron-starved cells of $R$. leguminosarum were resuspended to an $\mathrm{OD}_{600}$ of $0 \cdot 7 .{ }^{55} \mathrm{FeCl}_{3}$ was added in a solution of sodium nitrilotriacetate (NTA). The latter was made in a microcentrifuge tube by adding $1 \mu \mathrm{l}^{55} \mathrm{FeCl}_{3}(0 \cdot 242 \mathrm{MBq}$ in $0.1 \mathrm{M} \mathrm{HCl})$ to $200 \mu \mathrm{l} 2 \mathrm{mM}$ NTA. After $30 \mathrm{~min}$ equilibration at $30^{\circ} \mathrm{C}, 100 \mu$ l of the ${ }^{55} \mathrm{Fe}-$ NTA was added to $10 \mathrm{ml}$ of the cell suspension. Iron uptake was expressed as $\mathrm{ng}{ }^{55} \mathrm{Fe}$ (mg protein) $)^{-1}$.

Analytical methods. Protein determinations were carried out using the Bio-Rad protein assay. $\beta$-Galactosidase assays were performed according to Rossen et al. (1985), and the enzyme activity expressed in Miller units.

Siderophore analysis. Siderophore production was analysed using chrome azurol sulphonate (CAS) agar plates described by Schwyn \& Neilands (1987). Iron-starved cells $(10 \mu \mathrm{l}$ at $\mathrm{OD}_{600}$ of 0.7 ) were spotted onto the centre of the CAS-agar plates and incubated at $28^{\circ} \mathrm{C}$ for $3 \mathrm{~d}$. Siderophore production was seen as a bright orange halo around the bacterial growth.

Haem staining. Fractionation of Rhizobium cells into membrane and soluble fractions, followed by SDS-PAGE, blotting of the proteins and subsequent staining for haem was performed as described by Vargas et al. (1993).

Protoporphyrin IX detection. PPIX accumulation was measured by spectrofluorimetry (Miyamoto et al., 1992). $R$. leguminosarum strains were grown to stationary phase in $100 \mathrm{ml}$ complete TY medium. Cells were recovered by centrifugation, resuspended in acetone/0.1 $\mathrm{M} \mathrm{NH}_{4} \mathrm{OH}(9: 1$, $\mathrm{v} / \mathrm{v}$ ) and vortexed. Cell extracts were recentrifuged and the supernatants collected. Fluorescent emission spectra were recorded on a Howe Dr-15 spectrofluorimeter using an excitation wavelength of $405 \mathrm{~nm}$.

In vivo genetic manipulations. Plasmids were transferred into $R$. leguminosarum by conjugation as described by BuchananWollaston et al. (1980) using the plasmid pRK2013 as a helper in tri-parental matings (Figurski \& Helinski, 1979). Tn5lacZ mutagenesis of plasmid pKN16 was performed as follows. pKN16 was introduced by transformation to $E$. coli strain A118, which has a chromosomally located copy of TnSlacZ (Simon et al., 1989). This strain was used in a tri-parental mating (with pRK2013) in which $R$. leguminosarum biovar viciae strain $8401 \mathrm{pRL1JI}$ was the recipient. Selection was made on TY medium containing streptomycin (8401pRL1JI), plus kanamycin ( $\mathrm{Tn} 5$ lacZ) plus tetracycline (pKN16). Transconjugant colonies arose at a frequency of about $10^{-6}$ per recipient, these being due to the transfer of derivatives of pKN16 into which Tn5lacZ had transposed. Plasmid DNA was isolated from these transconjugants and, using appropriate restriction enzymes, the sites of insertion were roughly established, and the orientations of the lac $Z$ were determined.

For precise mapping of the feuQ::Tn5lacZ insertion, an internal BamHI restriction site in TnSlacZ and a HindIII site in the feuQ gene were used to generate a subclone in the sequencing vector pUC18. The junction between the end of IS50L and the pKN16 DNA was sequenced. This was done using a fluorescently labelled 25 -mer oligonucleotide primer with the sequence $5^{\prime}$ GAAGTCAGATCCTGGAAAACGGGAA 3', designed to bind to the end of Tn5.

The feuQ: : Tn 5 lacZ mutation in pKN16 was introduced into the R. leguminosarum genome by marker exchange (Ruvkun 
Table 1. Strains and plasmids

\begin{tabular}{|c|c|c|}
\hline Strain or plasmid & Relevant properties & Reference \\
\hline \multicolumn{3}{|l|}{ Strain } \\
\hline 8401pRL1JI & $\begin{array}{l}\text { R. leguminosarum bv. viciae carrying the symbiotic plasmid pRL1JI; } \\
\text { Str }^{r}\end{array}$ & Downie et al. (1983) \\
\hline A266 & Rifampicin-resistant derivative of $8401 \mathrm{pRL} 1 \mathrm{JI}$ carrying $c y c K 67:: \operatorname{Tn} 5$ & Delgado et al. (1995) \\
\hline A267 & Rifampicin-resistant derivative of $8401 \mathrm{pRL} 1 \mathrm{JI}$ carrying $c y c H 271:: \operatorname{Tn} 5$ & Delgado et al. (1995) \\
\hline 1062 & R. leguminosarum bv, viciae ura-14 trp-16 Str ${ }^{\mathrm{r}}$ & Beringer et al. (1978) \\
\hline Pop116 & Derivative of $1062 ; p o p-1$ & Nadler et al. (1990) \\
\hline $\mathrm{J} 100$ & Derivative of $8401 \mathrm{pRL} 1 \mathrm{JI}$ carrying feuQ: :Tn5lacZ & This work \\
\hline \multicolumn{3}{|l|}{ Plasmids } \\
\hline pIJ1942 & $\begin{array}{l}\text { Cosmid carrying } 30 \mathrm{~kb} \text { of } R \text {. leguminosarum DNA, including feuPQ, } \\
\text { lipA, cycHJKL }\end{array}$ & Delgado et al. (1995) \\
\hline pRK2013 & Helper plasmid & Figurski \& Helinski (1979) \\
\hline pKN16 & Similar to pIJ1942 & Nadler et al. $(1990)$ \\
\hline pMP220 & Broad-host-range cloning vector; Tet $^{r}$ & Spaink et al. (1985) \\
\hline pLAFR3 & Broad-host-range cloning vector; Tet $^{r}$ & Staskawicz et al. (1987) \\
\hline pRK415 & Broad-host-range cloning vector; Tet $^{r}$ & Keen et al. (1988) \\
\hline pIJ7345 & Derivative of pMP220 containing $c y c H J K L$ promoter region & This work \\
\hline pIJ7346 & Derivative of pMP220 containing lipA promoter region & This work \\
\hline pBIO260 & Derivative of pLAFR 3 containing feuPQ & This work \\
\hline $\mathrm{pBIO} 275$ & Derivative of pKN16 containing $c y c K:$ :Tn5lacZ & This work \\
\hline pBIO279 & Derivative of pKN16 containing feuQ: : Tn5lacZ & This work \\
\hline pBIO280 & Derivative of pKN16 containing feuP : :Tn 5 lacZ & This work \\
\hline pCHO8 & Cloned $c y c H J K$ genes of $S$. meliloti strain 41 cloned in pRK290 & Kereszt et al. (1995) \\
\hline pCHO8: : $\operatorname{Tn} 5(87)$ & Derivative of $\mathrm{pCHO} 8$ with $\mathrm{Tn} 5$ in $c y c K$ & Kereszt et al. (1995) \\
\hline
\end{tabular}

\& Ausubel, 1981) using the P1 incompatibility plasmid pPH1JI to eliminate the pKN16 as described by Downie et al. (1983). Pea seedlings (cv. Wisconsin Perfection) were inoculated, grown and assayed for nitrogen fixation as described by Beynon et al. (1980).

DNA manipulations. Restriction enzymes and DNA ligase were used according to the manufacturer's instructions. Transformation of $E$. coli was done according to Maniatis $e t$ al. (1982). DNA sequencing was done with the aid of an ALF (Pharmacia) semi-automated sequencer according to the manufacturer's instructions. The data were analysed using programs in the DNA-Star package. DNA searches of the EMBL database were carried out using BLAST in the GCG package.

The genes feuP and $f e u Q$ were amplified by PCR using the primers 5' CTCCTGCAGTCGATTTGAAAGCGGGACG 3' and $5^{\prime}$ CTCCTGCAGCGAGGCACTCTTCGTCGTGC 3', designed to bind 30 bp upstream of the $5^{\prime}$ end of $f e u P$ and 187 bp downstream of the $3^{\prime}$ end of $f e u Q$, respectively. A PstI site was engineered into the $5^{\prime}$ end of each primer to facilitate direct cloning of the PCR product into the sequencing vector pUC18. The fidelity of the PCR product was checked by sequencing; this product was then recloned into the broadhost-range plasmid pLAFR3 to form pBIO260.

\section{RESULTS AND DISCUSSION}

\section{Phenotypic similarity of Pop116 and Cyc mutants}

The previously described phenotypes of the Pop116 mutant of $R$. leguminosarum had some similarities to those of strains with mutations in $c y c H$ (strain A267) or $c y c K$ (strain A266). All three strains induced pea root nodules that contained bacteroids, but which failed to fix nitrogen. They were also defective in $c$-type cytochrome synthesis. Further, we noted that the pop116 mutation of $R$. leguminosarum (Nadler et al., 1990) and the cycHJKL genes of $S$. meliloti (Kereszt et al., 1995) were in corresponding positions of the highly conserved (Kondorosi et al., 1980) chromosomes of the two species. Given these similarities, strains Pop116, A266 and A267 were examined further to ascertain if they shared all their previously described phenotypes. Delgado et al. (1995) showed that mutants A266 and A267 did not catalyse the synthesis of indophenol blue from $N, N$ dimethyl- $p$-phenylenediamine and $\alpha$-naphthol (NADI test), indicating their loss of cytochrome $c$ function (Jones \& Poole, 1985). In an NADI test, colonies of the wild-type $R$. leguminosarum strain 1062 stained blue $\left(\mathrm{NADI}^{+}\right)$, but colonies of the Pop116 mutant derivative were white $\left(\mathrm{NADI}^{-}\right)$. Therefore, Pop116 was also unable to respire via the cytochrome $a a_{3}$ pathway.

Delgado et al. (1995) also showed that mutations in $c y c H$ and $c y c K$ blocked the formation of $c$-type haem proteins in $R$. leguminosarum. Membrane and soluble fractions from cells of strains 1062 and Pop116 were analysed for such proteins. As found previously (Delgado et al., 1995), the wild-type had two c-type haem proteins, of 23 and $31 \mathrm{kDa}$, in the membrane fraction and one $c$-type haem protein of $14 \mathrm{kDa}$ in the soluble fraction. In contrast, the mutant Pop116 had no detectable $c$-type protein in either fraction (results not shown). 


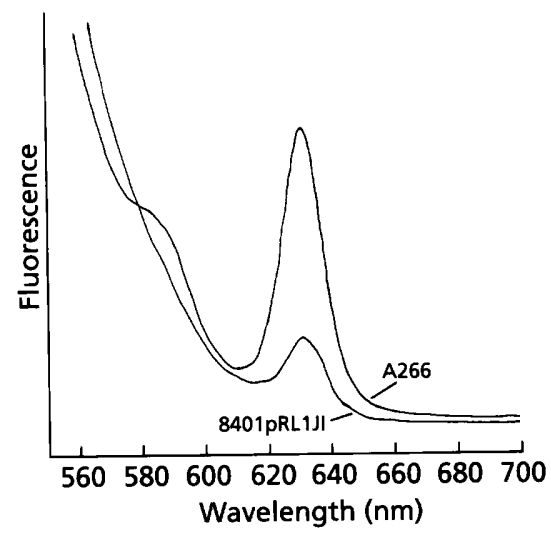

Fig. 1. Fluorescence spectra of extracts of $R$. leguminosarum strains $8401 \mathrm{pRL} 1 \mathrm{JI}$ and A266. The extracts were excited at $405 \mathrm{~nm}$, and emission measured at $633 \mathrm{~nm}$.

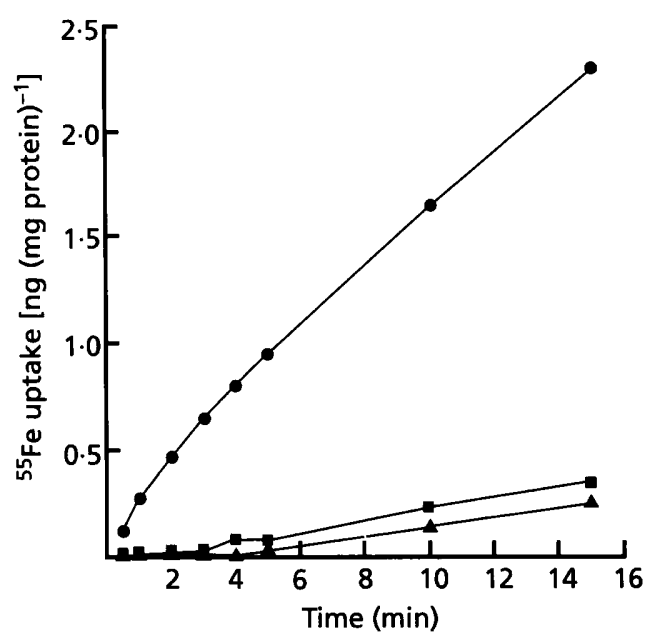

Fig. 2. ${ }^{55} \mathrm{Fe}$ uptake by $R$. leguminosarum strains grown in lowiron minimal medium broth. $0,8401 \mathrm{pRL} 1 \mathrm{JI} ; \mathbf{\square}, \mathrm{A266} ; \mathbf{\Delta}, \mathrm{J100}$.

The mutant Pop116 had two further characteristics, namely an accumulation of PPIX and a defect in iron uptake. As shown in Fig. 1, strain A266 was also found to accumulate PPIX (by approximately fivefold) relative to the wild-type strain $8401 \mathrm{pRL} 1 \mathrm{JI}$. In iron-uptake experiments, A266 was also found to be defective in this property (Fig. 2). The $c y c H$ strain A267 was identical to A266 in these two properties (not shown).

Some iron-uptake mutants are due to a defect in siderophore biosynthesis (Schwyn \& Neilands, 1987). The mutants A266, A267 and Pop116 were each tested for siderophore production, using CAS-agar plates. Siderophores remove the iron from the CAS-ferric dye complex, turning its colour from blue to orange. As expected, colonies of wild-type strains $8401 \mathrm{pRL} 1 \mathrm{JI}$ and 1062 had a bright halo. There was no such halo surrounding colonies of A266, A267 or Pop116, indicating that these mutants were unable to synthesize or export siderophores.
Taken together, these observations showed that the known phenotypic defects of Pop116 were very similar to those in the $c y c H$ and $c y c K$ mutants, and vice versa.

\section{The mutation in Pop116 is in cycK}

The $c y c H J K L$ operon that complements the A266 and A267 cyc mutants had been cloned on a pLAFR1-based plasmid, pIJ1942 (Delgado et al., 1995). Similarly, Nadler et al. (1990) isolated a pLAFR1-based plasmid, pKN16, which complemented the defects of the mutant Pop116. Digestion of pIJ1942 and pKN16 with EcoRI revealed almost identical restriction fragment patterns for the two plasmids, indicating that they contained cloned DNA in common. When mobilized into the mutants A266 and A267, pKN16 was able to restore the NADI, ${ }^{55} \mathrm{Fe}$ acquisition, nitrogen fixation and siderophore defects to normal. Likewise, when pIJ1942 was mobilized into Pop116, it corrected all its mutant phenotypes.

To determine which gene was mutated in Pop116, pKN16 was mutagenized with Tn5lacZ and mutant plasmids were screened for those that no longer corrected Pop116, as determined by the NADI test. One mutant plasmid, pBIO275, was unable to correct Pop116 for any of its defects. By restriction mapping, the Tn5lacZ was shown to be located in $c y c K$, approximately 500 bp upstream of $c y c L$. Delgado et al. (1995) proposed that $c y c K$ and $c y c L$ were translationally coupled; thus, in pBIO275, cycL may also be defective. However, we found that a plasmid, pCHO8 (Kereszt $e t$ al., 1995), which contained the cloned $c y c H J$ and $K$ (but lacked $c y c L$ ) genes of $S$. meliloti, also restored Pop116 to $\mathrm{NADI}^{+}$but that $\mathrm{pCHO} 8:: \operatorname{Tn} 5(87)$, a derivative with Tn5 in $c y c K$, did not. These observations show that the mutation in Pop116 is in $c y c K$, and that the $c y c K$ gene products of Rhizobium and Sinorbizobium are functionally interchangeable. [Johnston et al. (1994) reported tha the Pop ${ }^{-}$phenotype was corrected by a fragment of DNA containing the feuPQ genes, previously termed popPQ. That observation was erroneous.]

\section{Genes upstream of cycHJKL are predicted to encode an outer-membrane lipoprotein and a two- component transcriptional regulator}

During the course of sequencing the $c y c H J K L$ operon, three genes upstream of $c y c H$ were identified (Fig. 3).

The gene immediately upstream of $c y c H J K L$ was termed lipA; this gene is in the same orientation as $c y c H$ and encodes a protein of predicted molecular mass $13.5 \mathrm{kDa}$. The LipA protein appears to be a lipoprotein on the basis of its sequence, the best match being to the $17 \mathrm{kDa}$ antigenic outer-membrane protein described from several Rickettsia species. There is also a distinctive SerGlyCys (SGC) motif located at amino acid residues 13-15, which is a potential peptidase cleavage sequence, typical of outer-membrane lipoprotein cleavage sites (Wu \& Tokunga, 1986). Database searches also revealed 


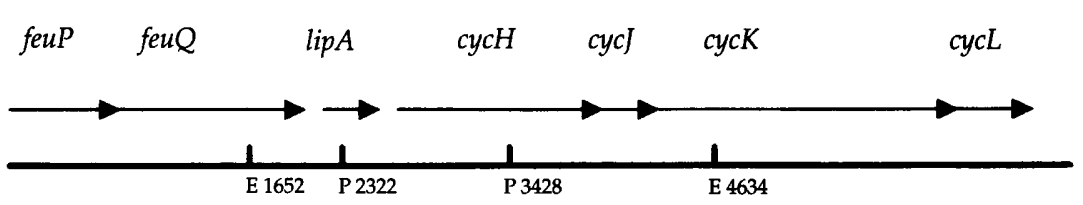

$\underset{\text { PIJ7346 }}{2 a c Z}$

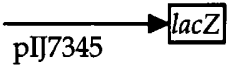

$1 \mathrm{~kb}$
Fig. 3. Locations of the feuPQ and lipA genes in relation to the $C y C H J K L$ operon. The arrows indicate the orientation of these genes and the numbers refer to the base pair positions in the DNA sequence. The fragments cloned to form the two lacZ fusion plasmids plJ7345 and plJ7346 and the positions of restriction sites for EcoRI (E) and Pstl (P) are shown.

\begin{abstract}
MRIKSLTARVLILTTVWSTVALVVIGLILISTLYRKSAERGFQDLLRAQLY FeuQ 50
NVINSVTIGDQGALSGSPQLGDLRFAQPKTGWYWVVEPLGTYTTAPLVSP FeuQ 100
\end{abstract}

SLGSALIPVP SVVEAPFDKNYERYYQVTDASGNRVQVAETEVVLDTDGRA FEUQ 150

ARVRVTGNVDVVEDDVRTESHSLYIALAGEGVGSLIVNALAILYGLKPLD FeuQ 200

KARAAWE. . RIRAGESEOLKGDFPRE ILPLANEVNALIDSNRRIVERARM FeUQ 248 KARAAWE...RIRAGESEQLKGDFPRE ILPLANEVNALIDSNRRIVERARM FeUQ 248 $\begin{array}{lll}\text { IEALAKEVRELEEHNRELLNPATTRELTSLVRNLNRLLKSERERYDKYRT } & \text { PhOQ } 270 \\ \text { HAALQVG.....KGIIPPPLREYGASEVRSVTRAFNH.MAAGVKQLADDRT ENVZ } & 235\end{array}$ RAAERLS..... MDLNTQPVP IDGPSVVQEAARAMNR.MQQRIQDLIRNRT QISA 218 ****

Q...VGNLAHSLKTPIAVLLNEARVLEK..... SHGELVR.SQAEAMQGQ FeuQ 289 T...LTDLTHSLKTPLAVLQSTLRSLRSEKMSVSDAEPVMLEQISRISQQ PhOQ 317 ..LLMAGVSHDLRTPLTRIRLATEMMSEODGYLAESINKDIEECNAI I .. ENVZ 282 QML. . AAISHDLRTP I TRMKLRAQEL. .DNSTTRNALVKDLNEMEVMINE QRSA 264

VQSYLNRARIAA......QRESVLARTDAEPALERLVRVMRRLNVDTEFD FEUQ 333 IGYYLHRASMRGGTILSRELHPV. . APLLDNLTSALNKVYORKGVNISLD PhOQ 365

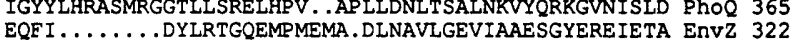
TLSF...........ARDDFADNAKVN.. LDLVSLVCSLVESMQDMGYNIQFH OrSA 304 * * * *

LVVSPPHLAVAMEQQDLEETVGNLLENAARFAKSRVRISAVEAAEDVKGV FeUQ 383 I...SPEISFVGEQNDFVEVMGNVLDNACKYCLEFVE........... I PhOQ 400 LYPGSIEVKMHPLSIKRA . VANMVVNAARYG...NGWI . . . . . . KV Env2 358 SHPQRIKILGRASALKRAFT..NLLNNAIRYAKNVNV.........RI QrSA 341

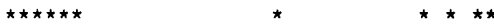

EASARRHWVELAVEDDGPGLEPDOIREALKRGRRSNESK.....PGTGLGL FeuO 429 SARQTDEHLY IVVEDDGPGIPLSKREVIFDRGQRVDTLR..... PGQGVGL PhOQ 446 SSGTEPNRAWEQVEDDGPGIAPEQRKHLFQPFVRGDSARTI...SGTGLGL ENVZ 406 QW. .RQNRVKVL IEDDGPGIAEKELEQVFEPFYRGEHSRSRDTGGVGLGL QrSA 389

$$
\text { ** }
$$

SIVTEISNEYOGRLELSRGE. . WGGLKAKLILP. . . GVTKDVA. . . AVAREITEOYEGFTKIVAGESMIGGARMEVIFGROHSAPKDE ....

AIVQRIVDN . HNGMLEIGTSERGGLSIRAWLPVDVTRAOGTTKEG

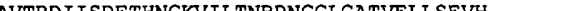

Fig. 4. Sequence comparisons of the deduced amino acid sequence of $R$. leguminosarum FeuQ with other sensor proteins: E. coli PhoQ; E. coli EnvZ; Coxiella burnetii QsrA. The residue number of each protein is provided at the end of each line. Amino acid residues that are common to all sequences are indicated by asterisks. Two hydrophobic domains of FeuQ from $R$. leguminosarum (residues 10-32 and 173-197) are underlined. The position of the Tn5lacZ insertion is marked with a triangle.

that the $3^{\prime}$ region of a homologue of $\operatorname{lip} A$ is present in $S$. meliloti, also upstream of $c y c H$ (Kereszt et al., 1995).

Upstream of lipA in R. leguminosarum, we identified two other genes; it was clear from the sequences of their predicted products that they belonged to the large family of two-component transcriptional regulators. These regulators tend to comprise two protein components. The 'sensor' protein is often located in the cytoplasmic membrane, and monitors the external cell environment. In response to particular environmental signals, the sensor protein usually phosphorylates or otherwise modifies a cytoplasmic 'response regulator' protein. The response regulator is usually a DNA-binding protein that, depending on its state of phosphorylation, can act as a transcriptional activator at one or more 'target' promoters (Parkinson \& Kofoid, 1992). The most similar gene products to those of the genes identified here were PhoP and PhoQ of E. coli. Given this similarity and their role in iron uptake (see below), the genes were termed feuP and feuQ (ferric uptake).

The FeuQ protein has a predicted molecular mass of $51.2 \mathrm{kDa}$, and has significant homology to sensor proteins belonging to the family of histidine protein kinases. In database searches, 40 such sensors with similarity to FeuQ were found. The conserved domain of these proteins extends over approximately 250 amino acids and is usually located at the C-terminus (Albright et al., 1989). FeuQ has four highly conserved regions when compared to other sensor proteins. Region 1 extends between amino acid positions 252-262 (Fig. 4) and contains a conserved histidine at position 255 , this being the putative site of autophosphorylation. Region 2 extends between positions 347-361 and has conserved asparagine and alanine residues at positions 356,360 and 361. Regions 3 and 4, between positions 396-405 and 423-432, respectively, are glycine-rich and resemble nucleotide-binding motifs (Parkinson \& Kofoid, 1992). These blocks of conserved amino acid residues probably form the catalytic centre involved in phosphorylation (Stock et al., 1989). The N-termini of sensor proteins tend to be variable and this region may contain the motifs needed to identify the specific environmental signals (Albright et al., 1989). Residues 10-32 and 173-197 of FeuQ are hydrophobic (Fig. 4), consistent with their being transmembrane domains. This would be consistent with residues 33-173 being exposed to the periplasm, with the C-terminal end of the protein exposed to the cytoplasm. A database search of residues 33-172, which probably form part of the sensor domain, showed no significant homology to any other sensor proteins.

The predicted feuP gene overlaps the predicted translational start of feuQ by 11 nucleotides, suggesting translational coupling. The $f e u P$ gene encodes a protein of predicted molecular mass $24.9 \mathrm{kDa}$, with similarity to many response regulator proteins. These include the PhoP of E. coli and Salmonella typhimurium $(67 \%$ identify) and the basR gene product of Haemophilus 


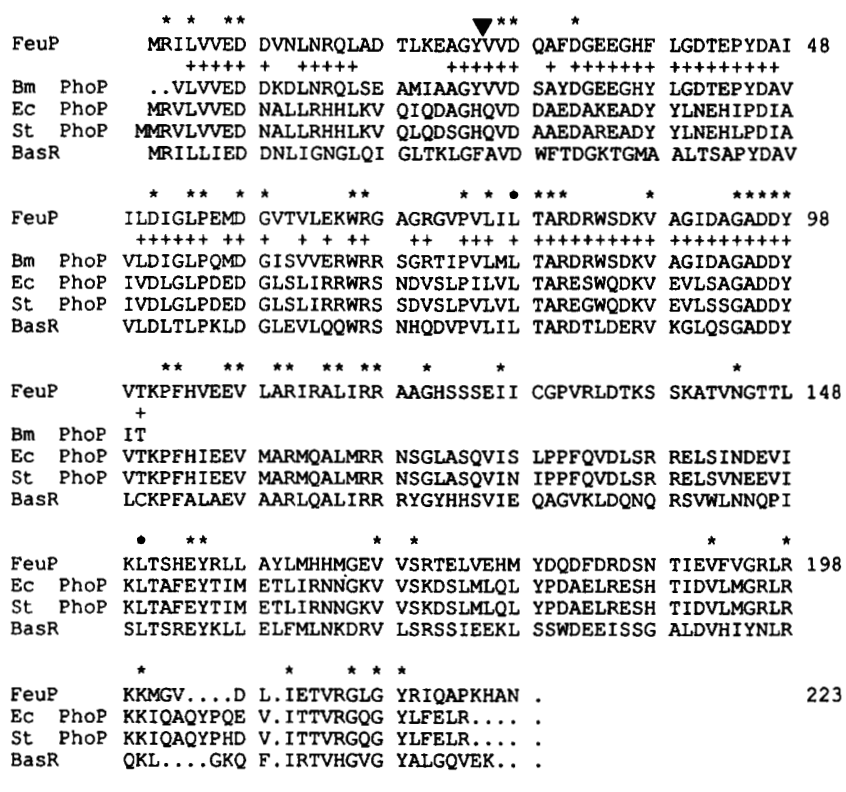

Fig. 5. Sequence comparisons of the deduced amino acid sequence of $R$. leguminosarum FeuP with those of other proteins: B. melitensis (Bm) PhoP; E. coli (Ec) PhoP; S. typhimurium (St) PhoP and $H$. influenzae BasR. The residue number of FeuP is provided at the end of each line. Amino acid residues identical in both $R$. leguminosarum FeuP and $B$. melitensis PhoP are indicated by crosses. Amino acids common to all sequences are indicated by asterisks. The position of the $\mathrm{Tn} 5 / \mathrm{acZ}$ insertion is marked with a triangle.

influenzae (61\% identity). These DNA-binding regulatory proteins tend to be similar to each other throughout their length; an alignment of FeuP with the response regulators mentioned above is shown in Fig. 5. An acid pocket is a feature of these regulatory proteins; thus, these residues are conserved among all sequences (Parkinson \& Kofoid, 1992). The residues in FeuP that correspond to Glu-7, Asp-8, Asp-9 and Asp-51 probably form part of the acid pocket into which the side chain of Lys-101 protrudes. The Asp residue at position 51 could be the site of phosphorylation by FeuQ (Parkinson \& Kofoid, 1992).

In addition to these similarities, there is a much stronger identity between FeuP and the deduced product of a partially sequenced region of DNA in the pathogen Brucella melitensis (Fig. 5), a close relative of Rhizobium (Woese, 1987). The identity (92\% at the amino acid level) is so high as to suggest that the $B$. melitensis gene may encode a protein that is functionally equivalent to FeuP (B. W. Wren, personal communication).

\section{A mutation in FeuQ affects iron uptake}

To determine the phenotype of a feu mutant strain, plasmid pKN16 was mutagenized with Tn5lacZ. Transposon insertions in the feuPQ region were identified initially by restriction mapping and were located precisely by DNA sequencing. One Tn 5 lacZ insertion in $f e u Q$ was isolated; precise mapping showed that $l a c Z$ was transcribed in the opposite orientation to feu $Q$ and so was not under the control of the feuPQ promoter. The feuQ: :Tn5lacZ insertion in this mutant plasmid (termed pBIO279) was marker-exchanged into the corresponding region of the genome of the wild-type $R$. leguminosarum strain $8401 \mathrm{pRL} 1 \mathrm{JI}$. DNA hybridization of genomic DNA using a probe that spanned feuPQ confirmed that a recombinant strain, termed J100, had undergone homologous recombination. This mutant was prototrophic, produced wild-type levels of siderophore, was $\mathrm{NADI}^{+}$and formed nitrogen-fixing nodules on the roots of peas. J100 did not accumulate PPIX at more than normal levels. However, J100 did have one striking characteristic in common with strains A266, A267 and Pop116 in that it also had a significantly reduced rate of ${ }^{55} \mathrm{Fe}$ uptake (Fig. 2). This phenotype was corrected by plasmid pBIO260, which contains a PCR product comprising feuPQ cloned in the broad-hostrange plasmid pLAFR3.

We also wished to determine the effects of a feuP mutation. A TnSlacZ insertion into the feuP gene in pKN16 was isolated, the orientation of the insertion being such that lac $Z$ would be transcribed from the feuPQ promoter. Repeated attempts to marker-exchange this mutation into the corresponding position in the chromosome of $R$. leguminosarum strain $8401 \mathrm{pRL} 1 \mathrm{JI}$ failed. It may be that under the conditions used here, feuP genomic mutants are non-viable or are slow-growing and thus difficult to isolate. Such an observation is not unprecedented; Osteras et al. (1995) reported an essential two-component regulatory system in Rhizobium spp.

\section{Effect of a feuQ mutation on the transcription of lipA and $C y C H J K L$}

Two-component regulators often control the transcription of nearby genes. Given the close linkage of feuPQ and $c y c H J K L$, plus the similarity of the effects of mutations in these genes with respect to iron uptake, the effects of the feuQ mutation on the transcription of the cycHJKL operon and also of lipA were tested.

Fragments spanning the $177 \mathrm{bp}$ intergenic region between lipA and $c y c H$ and the 118 bp region between feuQ and lipA (Fig. 3) were each cloned into the widehost-range promoter probe plasmid pMP220 to form pIJ7345 and pIJ7346, respectively. In these plasmid fusions, the levels of transcription of lacZ in pMP220 depend on the native promoter activity in the two intergenic sequences. Each plasmid was mobilized into the wild-type strain $8401 \mathrm{pRL} 1 \mathrm{JI}$ and into the feuQ mutant strain J100. As shown in Table 2, the lipA-lacZ fusion (pIJ7346) had considerably higher levels of activity than the $c y c H-l a c Z$ fusion. Comparison of the levels of $\beta$-galactosidase activities of both fusions in the wild-type and in the feuQ mutant strain $\mathrm{J} 100$ shows that the feuQ mutation has no effect on the expression of either the lipA or $c y c H$ fusion (Table 2).

Since the $c y c H J K L$ and feuQ genes play a role in iron uptake, measurements of the $c y c H-l a c Z$ and the lipA-lacZ activities were also made in cells of 
Table 2. $\beta$-Galactosidase activities of wild-type (8401pRL1JI) and feuQ mutant (J100) carrying a cycHJKL (pIJ7345) or lipA (pIJ7346) fusion plasmid

\begin{tabular}{|lcc|}
\hline Strain & \multicolumn{2}{c|}{$\boldsymbol{\beta}$-Galactosidase (Miller units) } \\
\cline { 2 - 3 } & Succinate + Fe & Succinate - Fe \\
\hline 8401pRL1JI(pMP220) & $12 \pm 8$ & $14 \pm 5$ \\
8401pRL1JI(pIJ7345) & $405 \pm 90$ & $234 \pm 30$ \\
8401pRL1JI(pIJ7346) & $1626 \pm 59$ & $1080 \pm 35$ \\
J100(pMP220) & $63 \pm 10$ & $25 \pm 8$ \\
J100(pIJ1345) & $391 \pm 27$ & $347 \pm 30$ \\
J100(pIJ7346) & $1708 \pm 163$ & $1270 \pm 83$ \\
\hline
\end{tabular}

8401pRL1JI and J100 grown in iron-depleted medium. As shown in Table 2, the expression of both fusions was reduced by growth in the low-iron conditions. However, this was not affected by the feuQ genotype and may just be a reflection of the poor cell growth in the irondeficient medium.

\section{Why are $c y c H J K L$ mutants defective in iron uptake?}

The $c y c H J K L$ genes have been identified in a number of bacterial genera, in mitochondria and chloroplasts. These genes, which appear to form a single operon in Rhizobium, Sinorhizobium and Bradyrhizobium, have been shown by several groups (Delgado et al., 1995; Kereszt et al., 1995; Ritz et al., 1995) to have a possible role in the attachment of haem to apocytochrome $c$. Here, we have shown that mutations in the $c y c H J K L$ operon of $R$. leguminosarum lead to a number of other, unexpected, phenotypic defects, previously identified in the Pop116 mutant. These are the accumulation of PPIX and a lack of siderophore production leading, presumably, to a defect in high affinity iron uptake.

Interestingly, the upstream gene $f e u Q$, which with $f e u P$, appears to encode a two-component regulator, is also involved in iron acquisition. This suggested a role for $f e u P Q$ in the regulation of iron uptake. However, a mutation in $f e u Q$ does not affect PPIX accumulation, siderophore production, cytochrome $c$ function or expression of the $c y c H J K L$ operon. Thus, $c y c$ and $f e u Q$ mutants do not confer identical phenotypes. We considered the possibility that the loss of high affinity iron acquisition in both feuQ and $c y c$ mutants might be because functional $c y c H J K L$ genes are required for FeuQ to function (for example, for incorporation of haem into the FeuQ protein). However, if this were the case, one would have to argue that siderophore production is not regulated by FeuQ and that the absence of siderophore production in $c y c$ mutants is independent of the FeuQ-mediated regulator.

At present, we are unable to explain the precise basis of the role of the $c y c H J K L$ genes in siderophore synthesis or excretion. One possibility is their direct involvement in the transport of siderophores from the cytoplasm into the periplasm. Since the functions of the $c y c H J K L$ gene products are thought to be in the attachment of haem to apocytochrome $c$, this explanation seems unlikely, given the lack of any chemical similarity between haem (or any of its precursors) and any known Rhizobium siderophore molecule.

A more plausible explanation is that the biosynthesis of siderophores may require an electron transfer step involving a $c$-type cytochrome. Since $c$-type cytochromes are located mostly on the periplasmic side of the membrane, such a reduction could, in principle, occur in the periplasm simply by diverting electrons from the electron transport pathway into an enzyme or substrate required for siderophore biosynthesis.

Another, somewhat speculative model to explain why $c y c$ mutants do not synthesize (or export) siderophores relates to the mechanisms by which bacteria sense the concentration of available iron. This model suggests that the primary signal for the activation of genes involved in siderophore biosynthesis may be the concentration of haem in the bacterial periplasm. The $c y c H J K L$ mutants would accumulate haem in that compartment since it would not be sequestered by $c$-type cytochromes or other haem-containing proteins in the membranes or periplasm. Thus, such mutants might sense that the concentration of available iron is higher than is, in fact, the case; in consequence, genes involved in siderophore production would not be expressed. The accumulation of PPIX in the $c y c$ mutants could, in turn, be due to the stripping of iron from the excess haem, adding the metal to the inorganic iron pool.

Given the widespread occurrence of the $c y c H J K L$ genes in bacteria and organelles, it will be of interest to establish if the various phenotypic defects caused by mutations in the $c y c H J K L$ genes of $R$. leguminosarum are relevant to these other systems.

\section{ACKNOWLEDGEMENTS}

This work was funded largely by the BBSRC and by an EUHCM grant (930497) to M.J.D. We thank A. Kereszt for supplying strains and plasmids and B.W.Wren for communication of results prior to publication.

\section{REFERENCES}

Albright, L. M., Huala, E. \& Ausubel, F. M. (1989). Prokaryotic signal transduction mediated by sensor and regulator pairs. Annu Rev Genet 23, 311-336.

Beckman, D. L., Trawick, D. R. \& Kranz, R. G. (1992). Bacterial cytochrome $c$ biogenesis. Genes Dev 6, 268-283.

Beringer, J. E. (1974). R factor transfer in Rhizobium leguminosarum. J Gen Microbiol 84, 188-198.

Beringer, J. E., Hoggan, S. A. \& Johnston, A. W. B. (1978). Linkage mapping in Rhizobium leguminosarum by means of $\mathrm{R}$ plasmidmediated recombination. J Gen Microbiol 104, 201-207.

Beynon, J. L., Beringer, J. E. \& Johnston, A. W. B. (1980). Plasmids and host-range in Rhizobium leguminosarum and Rhizobium phaseoli. J Gen Microbiol 120, 421-429.

Buchanan-Wollaston, A. V., Beringer, J. E., Brewin, N. J., Hirsch, P. R. \& Johnston, A. W. B. (1980). Isolation of symbiotically 
defective mutations in Rhizobium leguminosarum by insertion of the transposon Tn5 into a transmissible plasmid. Mol Gen Genet 178, 185-190.

Crosa, J. H. (1989). Genetics and microbiology of siderophoremediated iron transport in bacteria. Microbiol Rev 53, 517-530.

Delgado, M. J., Yeoman, K. H., Wu, G., Vargas, C., Davies, A. E., Poole, R. K., Johnston, A. W. B. \& Downie, J. A. (1995). Characterisation of the $c y c H J K L$ genes involved in cytochrome $c$ biogenesis and symbiotic nitrogen fixation in Rhizobium leguminosarum. J Bacteriol 177, 4927-4934.

Downie, J. A., Hombrecher, G., Ma, Q. S., Knight, C. D., Wells, B. \& Johnston, A. W. B. (1983). Cloned nodulation genes of Rhizobium leguminosarum determine host-range specificity. Mol Gen Genet 190, 359-365.

Figurski, D. H. \& Helinski, D. R. (1979). Replication of an origincontaining derivative of plasmid RK2 dependent on a plasmid function provided in trans. Proc Natl Acad Sci USA 76, 1648-1652.

Fischer, H. M. (1994). Genetic regulation of nitrogen fixation in rhizobia. Microbiol Rev 58, 352-386.

Gilles-Gonzalez, M. A., Ditta, G. S. \& Helinski, D. R. (1991). A haemoprotein with kinase activity encoded by the oxygen sensor of Rhizobium meliloti. Nature 350, 170-172.

Guerinot, M. L. (1991). Iron uptake and metabolism in the rhizobia/legume symbiosis. Plant Soil 130, 199-209.

Johnston, A. W. B., Brightwell, G., Tibertius, A. \& Yeoman, K. H. (1994). Exopolysaccharide synthesis and haem production in Agrobacterium and Rhizobium - an unexpected link. In Proceedings of the First European Nitrogen Fixation Conference, pp. 91-94. Edited by G. B. Kiss \& G. Endre. Szeged, Hungary: Officiana Press.

Jones, C. W. \& Poole, R. K. (1985). Analysis of cytochromes. Methods Microbiol 18, 285-328.

Keen, N. T., Tamaki, S., Kobayashi, D. \& Trollinger, D. (1988). Improved broad-host range plasmids for DNA cloning in Gramnegative bacteria. Gene 70, 191-197.

Kereszt, A., Slaska-Kiss, K., Putnoky, P., Banfalvi, Z. \& Kondorosi, A. (1995). The $c y c H J K L$ genes of Rhizobium meliloti involved in cytochrome $c$ biogenesis are required for 'respiratory' nitrate reduction ex planta and for nitrogen fixation during symbiosis. Mol Gen Genet 247, 39-47.

Kondorosi, A., Vincz, E., Johnston, A. W. B. \& Beringer, J. E. (1980). A comparison of three Rhizobium linkage groups. Mol Gen Genet 178, 403-408.

Maniatis, T., Fritsch, E. F. \& Sambrook, J. (1982). Molecular Cloning: a Laboratory Manual. Cold Spring Harbor, NY: Cold Spring Harbor Laboratory.

Miyamoto, K., Nishimura, K., Musuda, T., Tsuji, H. \& Inokuchioo, H. (1992). Accumulation of protoporphyrin IX in light-sensitive mutants of Escherichia coli. FEBS Lett 310, 246-248.

Monson, E. K., Ditta, G. S. \& Helinski, D. R. (1995). The oxygen sensor protein, FixL, of Rhizobium meliloti. J Biol Chem 270, 5243-5250.

Nadler, K. D., Johnston, A. W. B., Chen, J. W. \& John, T. R. (1990). A Rhizobium leguminosarum mutant defective in symbiotic iron acquisition. J Bacteriol 172, 670-677.

Ohyama, K., Fukuzawa, T., Kohchi, T., Sano, T., Sano, S. \& Shirai, H. (1988). Structure and organisation of Marchantia polymorpha chloroplast genome. J Mol Biol 203, 281-298.

Osteras, M., Stanley, J. \& Finan, T. M. (1995). Identification of Rhizobium-specific intergenic mosaic elements within an essential two-component regulatory system of Rhizobium species. J Bacteriol 177, 5485-5494.

Page, M. D. \& Ferguson, S. J. (1995). Cloning and sequence analysis of the $c y c H$ gene from Paracoccus denitrificans; the $c y c H$ gene product is required for assembly of all $c$-type cytochromes, including cytochrome $c_{1}$. Mol Microbiol 15, 307-318.

Parkinson, J. S. \& Kofoid, E. C. (1992). Communication modules in bacterial signalling proteins. Annu Rev Genet 26, 71-112.

Pritchard, A. E., Seilhamer, J. J., Mahalingam, R., Sable, C. L., Venuti, S. E. \& Cummings, D. J. (1990). Nucleotide sequence of the mitochondrial genome of Paramecium. Nucleic Acids Res 18, 173-180.

Reigh, G. \& O'Connell, M. (1993). Siderophore-mediated iron transport correlates with the presence of specific iron-regulated proteins in the outer membrane of Rhizobium meliloti. J Bacteriol 175, 94-102.

Ritz, D., Thöny-Meyer, L. \& Hennecke, H. (1995). The $c y c H J K L$ gene cluster plays an essential role in the biogenesis of $c$-type cytochromes in Bradyrhizobium japonicum. Mol Gen Genet 247, 27-38.

Rossen, L., Shearman, C. A., Johnston, A. W. B. \& Downie, J. A. (1985). The nodD gene of Rbizobium leguminosarum is autoregulatory and in the presence of plant root exudate induces the nod $A B C$ genes. EMBO J 4, 3369-3374.

Ruvkun, G. B. \& Ausubel, F. M. (1981). A general method for sitedirected mutagenesis in prokaryotes. Nature $289,85-88$.

Schwyn, B. \& Neilands, J. B. (1987). Universal chemical assay for the detection and determination of siderophores. Anal Biochem 160, 47-56.

Simon, R., Quamlt, J. \& Klipp, W. (1989). New derivatives of transposon $\mathrm{Tn} 5$ suitable for mobilisation of replicons, generation of operon fusions and induction of genes in Gram-negative bacteria. Gene 80, 161-169.

Smith, M. J., Shoolery, J. N., Schwyn, B., Holden, I. \& Neilands, J. B. (1985). Rhizobactin, a structurally novel siderophore from Rhizobium meliloti. J Am Chem Soc 107, 1739-1743.

Spaink, H. P., Okker, R. J. H., Wijffelman, C. A., Pees, E. \& Lugtenberg, B. J. J. (1985). Promoters in the nodulation region of the Rbizobium leguminosarum symbiotic plasmid pRL1JI. Plant Mol Biol 9, 27-39.

Staskawicz, B., Dahlbeck, D., Keen, N. T. \& Napoli, C. A. (1987). Molecular characterisation of cloned avirulence genes from race 0 and race 1 of Pseudomonas syringae pv glycinae. J Bacteriol 169, 5789-5794.

Stock, J. B., Ninfa, A. J. \& Stock, A. M. (1989). Protein phosphorylation and regulation of adaptive responses in bacteria. Microbiol Rev 53, 450-490.

Thöny-Meyer, L., Fischer, F., Kunzler, P., Ritz, D. \& Hennecke, H. (1995). Escherichia coli genes required for cytochrome $c$ maturation. J Bacteriol 177, 4321-4326.

Vargas, C., McEwan, A. G. \& Downie, J. A. (1993). Detection of $c$ type cytochromes using enhanced chemiluminescence. Anal Biochem 209, 323-326.

Woese, C. R. (1987). Bacterial evolution. Microbiol Rev 51, 221-271.

Wu, H. C. \& Tokunaga, M. (1986). Biogenesis of lipoproteins in bacteria. Curr Top Microbiol Immunol 125, 127-157.

Received 13 June 1996; revised 5 August 1996; accepted 8 September 1996. 